\title{
CORRESPONDENCE
}

\section{Alveolar macrophages carbon load: a marker of exposure?}

\section{To the Editor:}

In the editorial accompanying our article reporting higher alveolar macrophage carbon in adults who cycled to work in London, ACKERMANN-LIEBRICH [1] speculated that "very short, high peaks of exposure contribute more to total load of inhaled pollutants and, thus, we ought to control not only the mean pollutant levels but avoid higher peaks." In our initial analyses, we found no association between airway macrophage carbon and highest single exposure black carbon concentration $\left(\mathrm{ng} \cdot \mathrm{m}^{-3}\right)$ [2]. Since we had not assessed the effect of multiple peaks, we performed an additional analysis using the number of peaks of black carbon $>10,000 \mathrm{ng} \cdot \mathrm{m}^{-3}$ over $24 \mathrm{~h}$ as an exposure variable. Peaks of black carbon $>10,000 \mathrm{ng} \cdot \mathrm{m}^{-3}$ in each subject were identified from visual inspection of the time/exposure graph of the portable aethalometer output (Magee Scientific AE51, Berkeley, CA, USA). We found a significant association between airway macrophage carbon and the number of peaks of black carbon $\left(\mathrm{r}^{2}=0.33\right.$, $\mathrm{p}<0.01, \mathrm{n}=27$; fig. 1 ). As expected, the number of peaks of monitored black carbon was higher in cyclists compared with non-cyclists (mean \pm SEM $6.14 \pm 1.0(n=14)$ versus $2.46 \pm 0.7(n=13)$; $\mathrm{p}<0.001$, unpaired t-test). We therefore agree with ACKERMANNLIEBRICH [1] that short-term exposure to high concentrations of freshly generated diesel soot should be considered when developing air pollution exposure-reduction policies.

\section{Chinedu Nwokoro, Rossa Brugha and Jonathan Grigg}

Centre for Paediatrics, Blizard Institute, Barts and the London School of Medicine and Dentistry, Queen Mary University of London, London, UK.

Correspondence: J. Grigg, Blizard Institute, Barts and the London School of Medicine and Dentistry, Queen Mary University London, 4 Newark Street, London E1 2AT, UK. E-mail: j.grigg@qmul.ac.uk

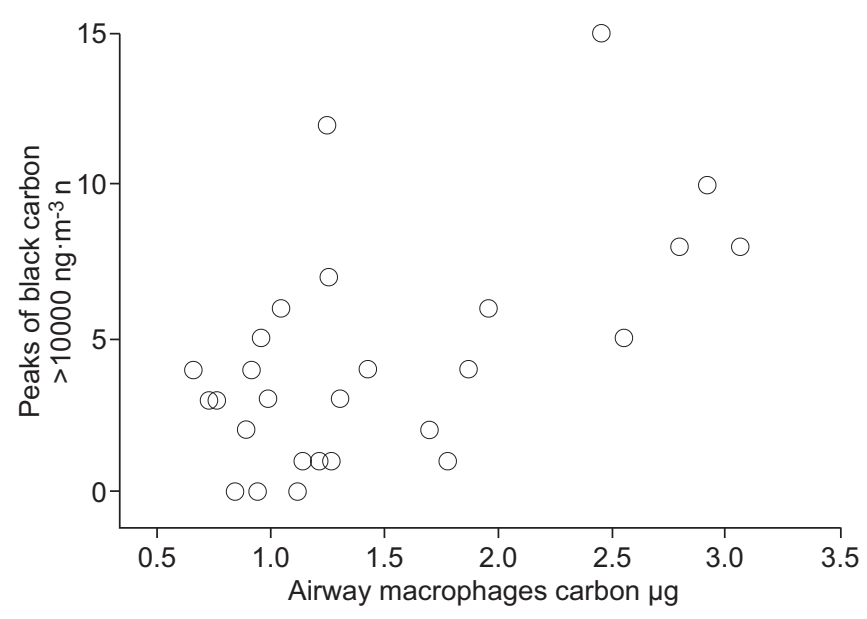

FIGURE 1. Scatter plot of airway macrophage carbon against the number of peaks of black carbon $>10,000 \mathrm{ng} \cdot \mathrm{m}^{-3}$. Airway macrophage carbon is expressed as the mean area of carbon $\left(\mu \mathrm{m}^{2}\right)$ from 50 macrophages per subject. Personal black carbon was monitored on a representative $24 \mathrm{~h}$ using a portable aethalometer. Exposure peaks were determined by visual inspection of timeconcentration plots. The association is significant $\left(r^{2}=0.33, p<0.01\right.$; Pearson $r$ test)

Support Statement: The study was supported by Barts and the London Charity.

Statement of Interest: None declared.

\section{REFERENCES}

1 Ackermann-Liebrich U. Alveolar macrophages carbon load: a marker of exposure? Eur Respir J 2012; 40: 1065-1066.

2 Nwokoro C, Ewin C, Harrison C, et al. Cycling to work in London and inhaled dose of black carbon. Eur Respir J 2012; 40: 1091-1097.

DOI: $10.1183 / 09031936.00176812$ 